\title{
Scientific basis of innovative development of the agro-industrial complex: the mechanism of public-private partnership in venture capital investment
}

\author{
Aleksei Bogoviz ${ }^{1, *}$, Ivan Sandu ${ }^{1}$, and Natalia Ryzhenkova ${ }^{1}$ \\ ${ }^{1}$ Federal Research Center of Agrarian Economy and Social Development of Rural Areas - All \\ Russian Research Institute of Agricultural Economics, 123007, Khoroshevskoye shosse, 35k2, \\ Moscow, Russia
}

\begin{abstract}
Relevance of the research: The article justifies the expediency of clarifying the scientific basis of innovative development of the agricultural sector in modern conditions. The purpose of this paper is to formulate proposals for using the principles of venture investment as the main tool for successful innovation development. Research methods: the major approach to the study of this problem is the use of the main provisions of the theory of development of innovation processes in the agro-industrial complex. Results of the research: the article clarifies the conceptual apparatus of "public-private partnership". In particular, the role and importance of the Russian Venture Company created for the formation of venture investment institutions in Russia is examined. In this connection, an algorithm for creating a model venture fund in the Moscow region is proposed, and the objectives and tasks of its activities, the functioning mechanism, including the financial block in terms of the distribution of investment along the stages of the innovation process are defined. Importance of the research: innovative development is currently the main driver of economic growth, which contributes to the emergence of new industries, increasing investment activity of economic entities and the growth of incomes and consumption. In turn, economic growth expands, firstly, the opportunities for the emergence of new products and technologies, secondly, increases investment in the development of human capital (primarily in education and basic science), and thirdly, supports innovations, which will have a multiplier effect on the pace of innovative development of the agricultural sector of the national economy.
\end{abstract}

\section{Introduction}

Today, in the era of investing in innovation and the transition of the real sector of economy to the path of innovative development, the scientific sphere, the sphere of production of economic entities of the agro-industrial complex (AIC) and business, which are the

\footnotetext{
* Corresponding author: aleksei.bogoviz@gmail.com
} 
initiators of the ongoing reforms in the industry, are clearly aware that only with increasing volumes of investment in direct production it will be possible to find a solution to the issue of the search for new approaches to the formation of organizational and economic mechanisms that promote effective introduction into production the newest scientific and technological achievements. They will allow redistributing investment resources, involving, in particular, in the commercial turnover as many innovative projects and ideas, based on the priorities of the industry development, as possible.

The best practices of the leading economies of the world in terms of business, as well as individual investors that have achieved the greatest positive results in mastering innovations show that in modern conditions such a mechanism can be represented by venture capital investment. Herewith, in domestic practice the mechanism of public-private partnership is seen as a basis for creating an institution of venture investment. At the same time, the state should play the key role in establishing the investment institution.

\section{Concepts}

The origin of the concept of "public-private partnership" (PPP) has a very extensive history associated with the respective English term. At the same time, up to this time, there is no unity in the scientific literature in understanding this institution. Many scientists (N.I. Oksanich, A.V. Naumkin, etc.) write about public-private partnership, while others emphasize private partnership as the first. At the same time, this difference is related to the source of investment: it can be both the state and private business. In practice, the notion of public-private partnership has settled, although individual scientists (V. Krutikov, O. Fedorova et al.) fundamentally use the formulation of private-public partnerships.

In our opinion, public-private partnership should be viewed as a new product that is based on the joint activities of the state and business, in order to implement priority innovative projects and programs in various regions of the country. Also the public-private partnership is aimed at minimizing shortcomings of the state regulation of the economic sphere, and all kinds of "market failures". The basis for using the mechanism of publicprivate partnership is the fact that both the public and private sectors have their own capabilities and advantages, which predetermines the formation of more effective tools that ultimately will allow achieving the most significant results in those industries and spheres where the shortcomings of development of the market economy in the domestic practice become particularly visible, making it possible to say about the inefficiency of public administration.

In this regard, it should be an objective necessity to use public-private partnership as an effective mechanism for extra-budgetary financing for the development of innovative infrastructure facilities. This is a consequence of the limited budget financing of capital investments that is due to the fact that when financing an innovative project, some difficulties connected with budgetary expenditures over time emerge, and as a result, state and municipal government bodies should take direct participation both at the initial stage of operation of the facility, and at its completion, when receiving income.

Researches of the agrarian scientists (I.S. Sandu, V.I. Nechaev, A.V. Bogoviz, et al) once again proved the thesis that in our country the mechanism of public-private partnership is still at the stage of formation $[2,3]$.

\section{Data and methodology}

When forming an institution of venture investment for the innovative development of the AIC, it is necessary to take into account the fact that at present, in order to form a domestic 
institution of venture investment and promote science-intensive technologies and products, in accordance with the order of the Government of the Russian Federation No. 838-r of June 7, 2006, the Russian Venture Company (OJSC RVC) was created, which is a conductor between the state (represented by the established JSC), regional venture funds, and innovative facilities [8].

As noted by the Academician I.G. Ushachev, the main task of RVC OJSC is the development of venture investment in the country, including through increased funding, in particular, sectoral venture capital funds, and in this case RVC acts as a conductor of the state venture capital funds [7].

At the initial stage of the formation of the Russian Venture Company as a structural unit of the Federal Agency for the Management of State Property of the Russian Federation, its authorized capital was 30011320.7 billion rubles. Only in 2007, there were more than 140 innovative companies where such were funds invested and which were created with direct participation of RVC. The volume of investment was above 13.05 billion rubles.

The priority area of the company's activities is investment in the development of Russian regions, including the agrarian sector. Thus, more than 28 agreements were signed at the regional level.

The main principle of the RVC's work is the implementation of the investment mechanism of the RVC funds that involves investing in those venture funds, which already have received private investors. The following proportion is the main condition for this: the share of RVC should be $49 \%$, and of private investors - 51\% [1].

As mention some experts in the field of financing the agrarian sector of the regional economy (A.A. Bobikov, A. Zakharov, A.V. Bogoviz, etc.), the investment shares should be accumulated to form an innovative infrastructure, the development of regional innovation formations, the creation of a new paradigm that unites science, education and business; with the aim of promoting domestic new innovative products, including technologies both on the internal and international markets; increasing demand for new innovations through the mechanism of stimulation of such demands; wide involvement of international venture capital investment practices in order to further develop partnerships. [1] As the research of the scientists of the All-Russian Research Institute of Agricultural Economics (I.S. Sundu, A.V. Bogoviz, N.E. Ryzhenkova, etc.) has shown, the formation of collective investment mechanisms should be considered as a separate direction $[4,6,8]$.

\section{Results and discussion}

The conducted studies (A.S. Troshin, A.A. Bobikov, etc.) showed, in particular, that the establishment of a venture fund in the agrarian sector of the Moscow region [1] can become a benchmark - the basis for increasing innovation activity of economic entities in the region that forms a regional innovation-investment system. At the same time, financial allocations in the fund should be replenished at the expense of the regional budget, financial resources of large regional agricultural producers of holding type, various investors (domestic and foreign) and business communities. However, as A.A. Bobikov, A.V. Bogoviz and other researchers note, in order to attract the RVC funds to the agrarian sphere of the Moscow region, a decision of the Government of the Moscow region on innovative formation is required to prepare a documentary investment project in the field of formation of the AIC venture fund, for example, in the form of a closed mutual investment fund, and also a search of investors for the developed innovative projects. The investment project should become a fundamental document of the fund and regulate its goals, objectives, organization principles and activities. $[4,6]$

As the experience of development of similar funds in various sectors of the national economy shows, the main objectives of the proposed venture fund, as A.A. Bobikov, A.V. 
Bogoviz and others believe, will be the following: establishment of a venture investment institution in the agrarian sphere of the Moscow region [1], and development of innovation and investment policy in the field of investment in innovative projects implemented in the agricultural sector of the economy of the Moscow region as an element of information support of the region (Figure 1) [1, 4].

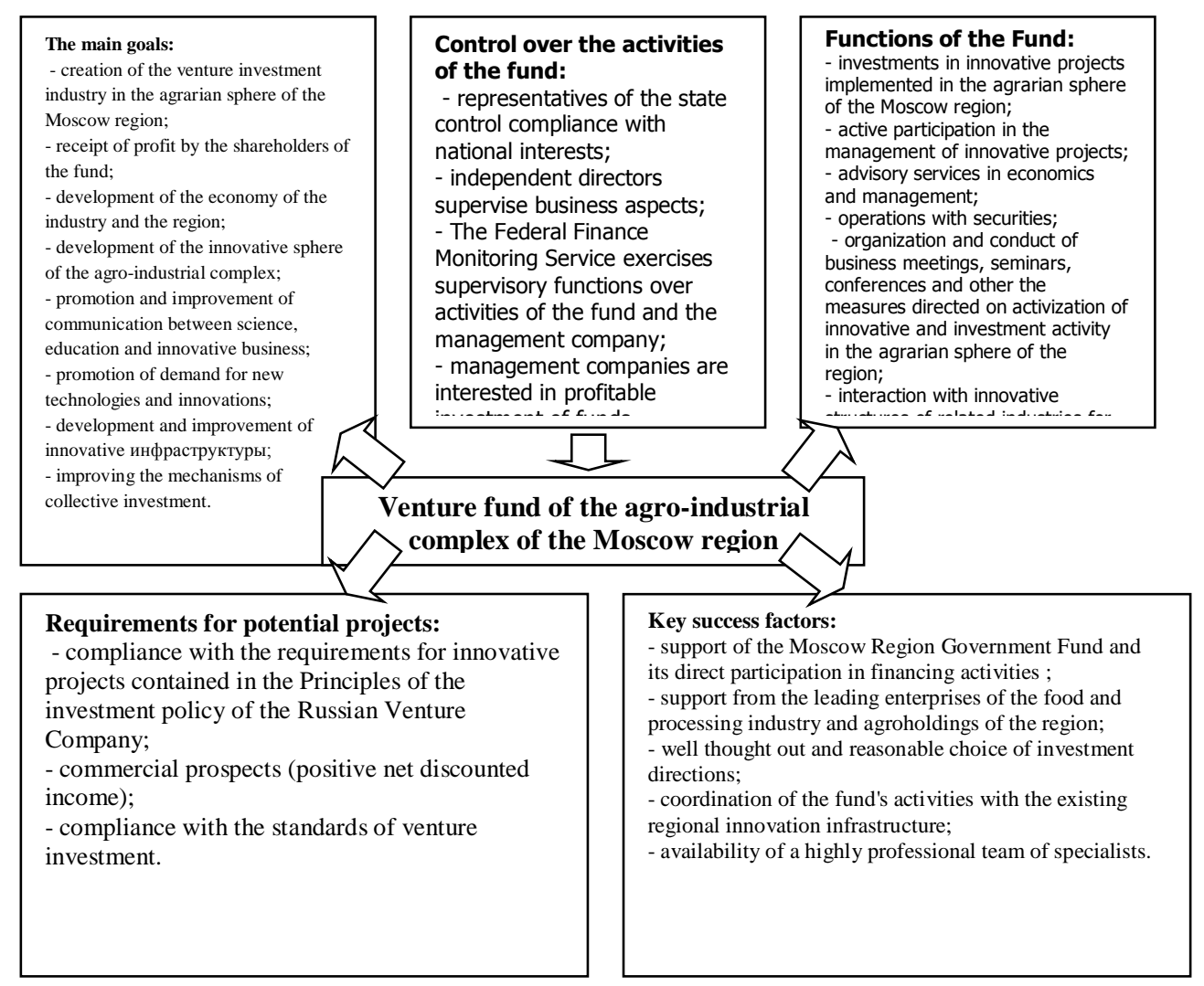

Fig. 1. The main objectives and tasks of the venture fund of the agro-industrial complex of the Moscow region [1, 4].

Herewith, as N.E. Ryzhenkova and N.V. Barsukova note, the funds of the Fund can be formed from three sources: funds from the regional budget; means of agricultural products processing enterprises; means of the interested investors; as well as the own funds of the management company $[5,6]$.

As noted by I.S. Sandu and A.S. Troshin, the interests of private investors should be taken into account when developing an algorithm of functioning of the Fund.

In the process of the Fund's activities, it is important to follow the generally accepted approaches for creating an innovative institution [1].

At the same time, the studies have shown that budget efficiency is ensured through the accelerated formation of the venture investment system and the rapid development of the most innovative company that in turn will increase tax revenues, lead to an increase in GRP and a qualitative improvement in its structure [5].

Thus, in order to form a fund, it is necessary to develop an algorithm for its creation and prepare an application for participation in the competition of management companies to be conducted by the RVC. 
Herewith, special attention should be given to the main criteria for the formation and evaluation of applications [4].

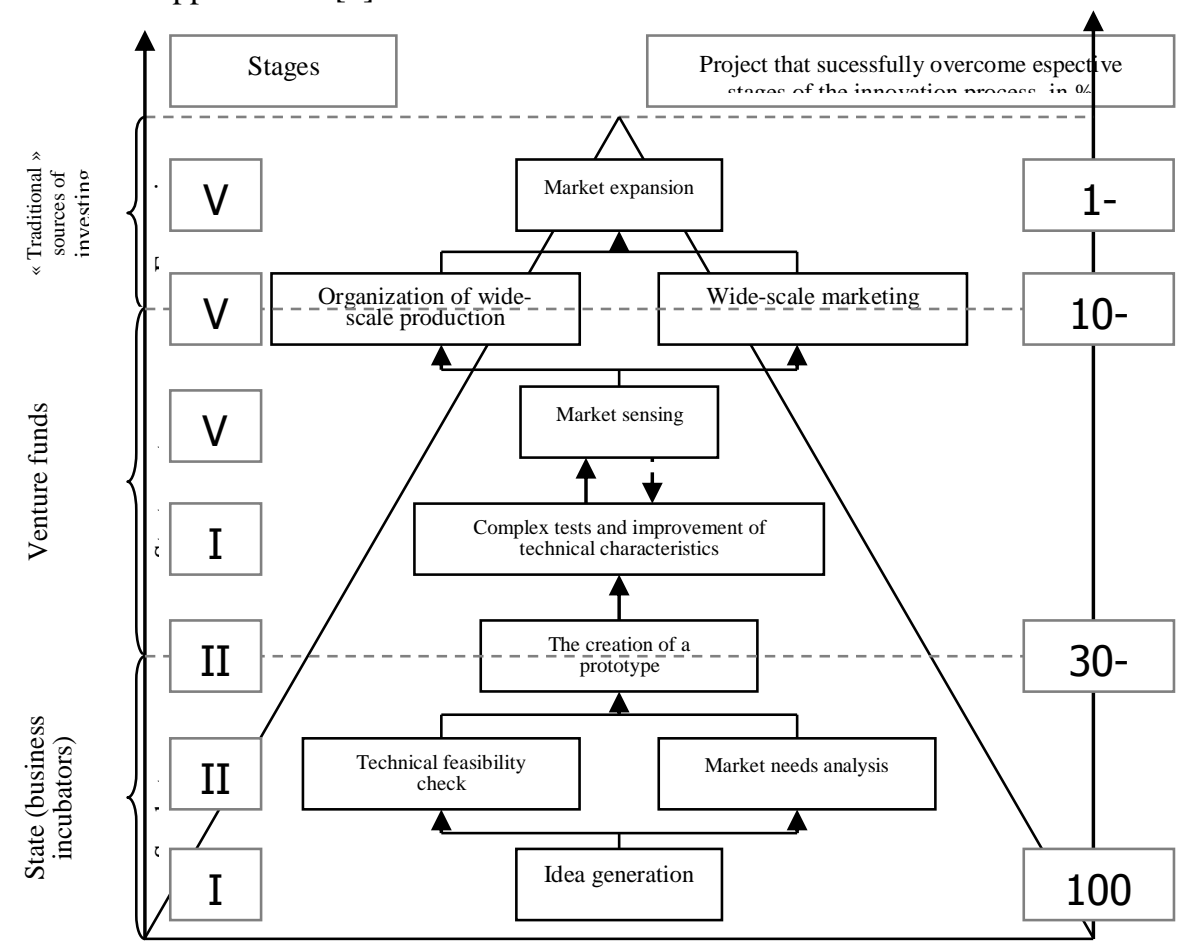

Fig. 2. Distribution of investors according to the stages of the innovation process $[1,4]$

As A.A. Bobikov, N.E. Ryzhenkova and A.V. Bogoviz indicate, in the future, between the entities forming the venture fund of the agro-industrial complex of the Moscow region, a contract should be concluded. Thus, this methodological approach will allow the venture company conducting annual monitoring of the use of funds. At the same time, it should be noted that the management company is obliged to make a pledge as a guarantee for the fulfillment of obligations [1].

Research conducted by the scientists of the All - Russian Research Institute of Agricultural Economics showed that only after passing through all stages of registration, the venture capital fund of the AIC of the Moscow region will have the right to issue investment resources, and within five years it will need to invest one project of the AIC venture fund every year [7].

At the same time, it is necessary to take into account that the venture fund will have to start investing in the absence of both a clear innovation and investment policy in the region, and a formed regional innovation system that includes science, business and production [9].

However, as noted by A.A. Bobikov, A.V. Bogoviz and N.E. Ryzhenkova, at present there are many shortcomings in the innovative sector of the economy: in particular, the lack of incentive mechanisms for investment activity influences certain stages, adversely affecting the entire innovation process. Along with this, the use of effective innovative projects is of interest to all subjects of the venture fund (Figure 2) [1].

All of the above will allow us to further define the procedure for the implementation of innovative projects in agricultural production and in the processing of agricultural raw materials. 
The study of the experience of the leading economies of the world in terms of the agricultural production made it possible to note that today, at the initial stage the financing of projects takes place through innovative institutions, the main function of which is to support and promote the development of small innovative formations to the stage of readiness for venture investments. [1, 9, 12] Thus, at the initial stage the venture fund should finance the formation of innovative infrastructure of the Moscow region's AIC, including the establishment of the institution of agricultural consulting in the Moscow region and the bank for innovative projects that will ultimately lead to the unification of all elements of the innovation infrastructure through the unified information system of the agro-industrial complex $[4,7]$.

\section{Conclusions}

At present, the agrarian science of Russia emphasizes that investments are not only funding to the expansion of fixed assets, but also the costs of replenishing and forming the current assets of an enterprise. Studies have shown that the increasing effectiveness of economic entities of the AIC of the Moscow region is connected, first of all, with the introduction of the latest achievements of scientific and technological progress, advanced experience and modern technological solutions. In this regard, the development of innovation involves the activation of investment activities as the basis for innovative projects, which requires permanent and long-term costs.

Long-term results of monitoring the financial and economic, and investment activities of the economic entities of the agro-industrial complex of the Moscow region show that, it is impossible to speak about transition of agriculture to the new path of development without a new policy in the field of the state support [1, 4].

The analysis of the best practices of the developed and developing countries that have made significant progress in innovations, including in the agrarian sector, confirms that the most promising form of venture capital investment is public-private partnership [3]. Therefore, in order to invest potentially high-performance innovative projects, which, due to the increased level of risks have difficulties with attracting financing, it is proposed to create the AIC venture fund.

Thus, it should be noted that the use of the institution of venture investment in the AIC in the Moscow region [1] should become the basis for the development of the socioeconomic sphere of the agro-industrial complex of the region, which in the future should contribute to solving the problem of financing at all stages of the innovation process and will allow forming a closed investment and innovation cycle, and, ultimately, ensuring the accelerated development of scientific achievements [1] by the economic agents of the regional AIC. Subsequently, this should ensure an increase in the pace of development and in the efficiency and competitiveness of the agribusiness sector and the entire economy of the region $[1,2,8]$.

\section{References}

1. A. A. Bobikov, Investments as a factor of effective development of innovations in agriculture (All-Russian Research Institute of Agricultural Economics, Moscow, 2007)

2. I. S. Sandu, N. E. Ryzhenkova, Methodical provisions for increasing the innovation and investment attractiveness of economic entities of the agroindustrial complex (Scientific consultant, Moscow, 2017) 
3. N. I. Oksanych, A. V. Naumkin, Public-private partnership in implementing agrarian policy (Voskhod, Moscow, 2010)

4. I. S. Sandu, F. V. Bogoviz, A. A. Bobikov, Problems and prospects of investment development of the agroindustrial complex of the Moscow region (Rosinformagrotekh, Moscow, 2007)

5. N. E. Ryzhenkova, Economics, Labor, Management in Agriculture, 3, 32 (2017)

6. I. S. Sandu, N. E. Ryzhenkov, A. S. Troshin, N. V. Barsukova, Innovation and investment, 2 (2015)

7. ARIAE, Agrarian and industrial complex innovative system formation: the mechanism of public-private partnership (ARIAE, Moscow, 2015)

8. I. S. Sandu, M. Y. Veselovsky, E. I. Semyonova, A. I. Doshchanova, Journal of Applied Economic Sciences, 6, 36 (2015)

9. A. S. Troshin, I. S. Sandu, A. V. Kupriyanov, E. A. Stryabkova, H. F. D. Saldanha, Life Science Journal, 11, 10s (2014)

10. M. Y. Veselovsky, S. U. Nuraliev, A. V. Fedotov, I. S. Sandu, N. D. Avarskiy, Journal of Applied Economic Sciences, 10, 3 (2015)

11. M. Y. Veselovsky, E. I. Semenova, A.V. Fedotov, A. Doshchanova, Journal of Advanced Research in Law and Economics, 6, 3 (2015)

12. I. S. Sandu, M. Y. Veselovsky, N. E. Ryzhenkova, Life Science Journal, 11, 12 (2014) 